Buxton, E. W. \& Richards, M. G. (1955). J. gen. Microbiol. 13, 99-102.

\title{
Pathogenic Strains of Fusarium oxysporum Fr. Distin- guished by their Differential Tolerance to Inhibition by various Actinomycetes
}

\author{
BY E. W. BUXTON AND MARILYN G. RICHARDS \\ Plant Pathology Department, Rothamsted Experimental \\ Station, Harpenden, Hertfordshire
}

SUMMARY : Cultures of sixteen different soil actinomycetes were tested for their ability to inhibit the growth of eight pathogenic strains of Fusarium oxysporum Fr. on agar media. Three of the actinomycetes dia not inhibit growth, and nine inhibited growth of all strains equally, but the other four actinomycetes consistently inhibited the growth of individual strains to different extents. The differences provide an in vitro test which distinguishes between certain pathogenic strains of Fusarium that are otherwise indistinguishable in culture.

Fusarium oxysporum Fr. is an Imperfect fungus comprising many pathogenic strains which are indistinguishable in culture. The complex system of classification proposed by Wollenweber \& Reinking (1935), in which many species were described, was simplified by Snyder \& Hansen (1940), who grouped all the members under the name $\boldsymbol{F}$. oxysporum $\mathrm{Fr}$. The many forms of this species cause wilt diseases of several important crops, e.g. banana, tomato, flax and peas. Each pathogenic strain is designated forma specialis according to its specific pathogenicity towards a particular host. Within these strains, physiologic races occur, the races differing in their abilities to cause disease in different varieties of the host. Eight members of the species $F$. oxysporum Fr. were grown in culture with sixteen actinomycetes to see whether the actinomycetes affected the growth of the fusarium strains and, if so, whether the inhibition was specific and in any way correlated with the pathogenicity of the fusarium strains.

\section{ME'THODS}

The eight fusarium strains used, with their laboratory numbers and origins, were as follows: $71 \mathrm{~B}$, Fusarium oxysporum f. pisi race 1, from wilted peas; $72 \mathrm{~B}, \boldsymbol{F}$. oxysporum f. pisi race 2 , from 'near-wilted' peas; $611 \mathrm{~A}, \boldsymbol{F}$. oxysporum f. pisi race $3 \mathrm{~A}$, from wilted peas (Buxton, 1955); $612 \mathrm{~A}, \mathrm{~F}$. oxysporum f. pisi, from wilted peas, equivalent in pathogenicity to $71 \mathrm{~B} ; 51 \mathrm{~A}, F$. oxysporum $\mathrm{F}$. (syn.F. oxysporum Fr.var. redolens $(\mathrm{Wr}$.), n. comb. Gordon, from wilted peas; F 1 , $\boldsymbol{F}$. oxysporum f. gladioli, yellowing strain from Gladiolus; F2, F. oxysporum f. gladioli, yellowing and rotting strain from Gladiolus; $61 \mathrm{~A}, \boldsymbol{F}$. oxysporum $\mathrm{Fr}$., non-pathogenic to peas, isolated from soil.

Sixteen actinomycetes, isolated from soil, were tested against the eight fusaria. The tests were made on medium constituted as follows: (g./l. water; $\mathrm{NaNO}_{2}, 2.0 ; \mathrm{K}_{2} \mathrm{HPO}_{4}, 1.0 ; \mathrm{MgSO}_{4} .7 \mathrm{H}_{2} \mathrm{O}, 0.5 ; \mathrm{KCl}, 0.5 ; \mathrm{FeSO}_{4} .7 \mathrm{H}_{2} \mathrm{O}, 0.01 ;$ 


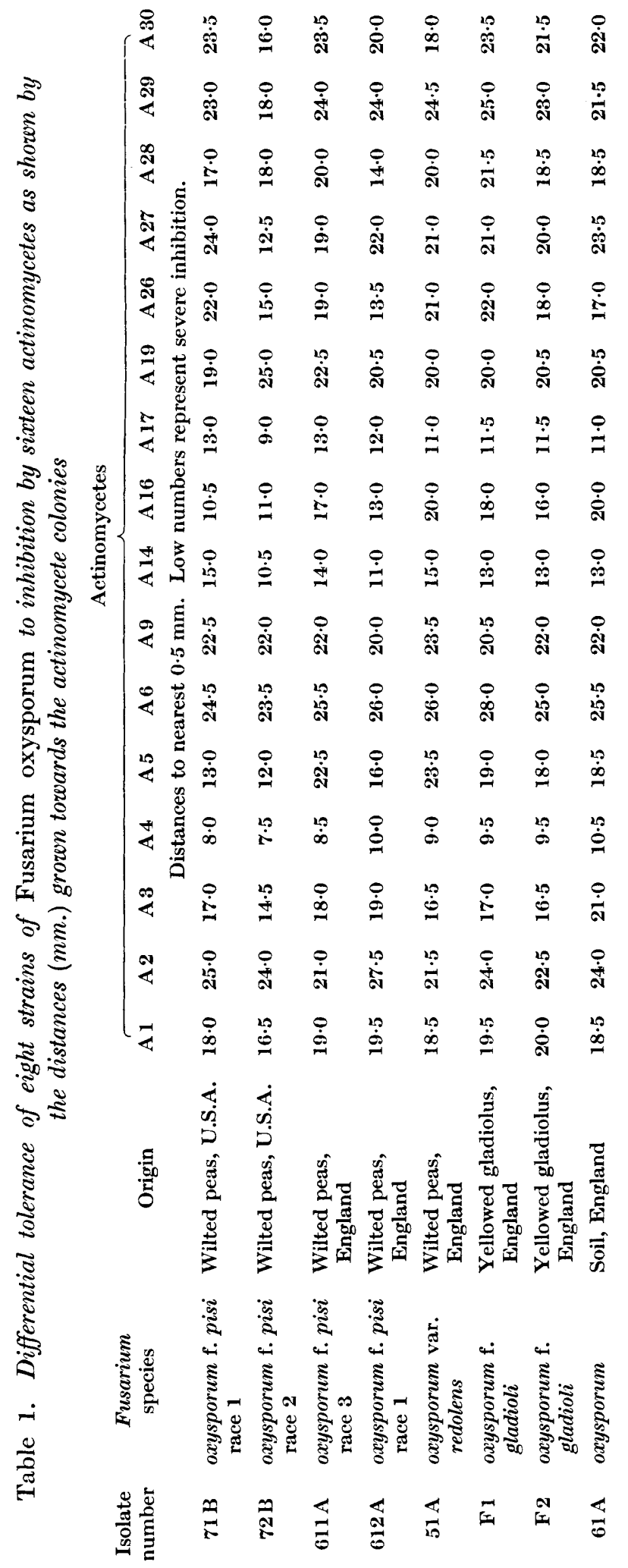


soluble starch, 10.0; Bacto-tryptone, $1.0 ;$ agar, 15; $\mathrm{pH}$ adjusted to $7 \cdot 0$ with a concentrated solution of $\mathrm{NaOH}$.

A single streak of an actinomycete was made on a Petri dish containing $10 \mathrm{ml}$. of the medium; this was then incubated for 5 days at $25^{\circ}$. A streak of a fusarium (as spore suspensions of uniform density) was then made parallel to the actinomycete colony and $30 \mathrm{~mm}$. distance from it. The plates were incubated for 5 more days before the growth of the fusarium towards the actinomycete was measured, these times having been found optimal for showing inhibition.

\section{RESULTS}

Three of the actinomycete colonies (A 4, A 14, A 17) strongly inhibited all eight fusaria, six (A 1, A3, A9, A 19, A 28, A 30) inhibited all less strongly, and three (A2, A6, A 29) allowed them to grow normally, so that the fusarium finally enveloped the actinomycete colony. Four of the actinomycetes (A5, A 16, A 26, A 27) inhibited different fusaria to different extents. Control streaks of the fusaria grew beyond the $30 \mathrm{~mm}$. lines after 6 days. Strongly inhibited fusarium strains had advancing edges which consisted entirely of tightly packed stunted hyphae, whereas partly inhibited strains had marginal hyphae which branched subnormally. The inhibition shown by actinornycete A5 (Table 1), identified as a strain of Streptomyces albidoflavus (Rossi Doria) Waksman \& Henrici, towards strains 72B ( $F$. oxysporum f. pisi, race 2 ) and $611 \mathrm{~A}$ ( $F$. oxysporum f. pisi, race $\mathbf{3 A}$ ) is shown in Pl. 1, fig. 1. Zones of inhibition by the same actinomycete on dishes seeded with fusaria are shown in Pl. 1, fig. 2. Culture filtrates of $S$. albidoflavus grown in liquid starch-tryptone medium (constituted as above) were tested against the fusarium strains. Porcelain cylinders containing $\mathbf{0} \cdot \mathbf{1} \mathrm{ml}$. of the filtrate were placed on the surface of dishes containing $10 \mathrm{ml}$. of starch tryptone agar medium seeded with spores of fusaria. Inhibition differences by the filtrates were analogous to those observed in the streak method and are shown in Pl. 1, fig. 3.

\section{DISCUSSION}

There is nothing new in the fact that growth products from actinomycetes should inhibit the growth of fusaria in culture or in the soil. Kublanovskaya (1952) suppressed wilt of cotton, caused by Fusarium vasinfectum, and Lachange \& Perrault (1953) wilt of flax, caused by $F$. lini, by adding actinomycetes to infected soil. Neither variations in the susceptibility of different pathogenic strains of Fusarium nor indeed variations in any strains of wild-type fungus to the action of actinomycete inhibitors, have been previously recorded. Mitchison (1951), however, found isolates of Mycobacterium tuberculosis with different abilities to tolerate streptomycin, and Katznelson \& Sutton (1953) detected different reactions of strains of Xanthomonas translucens to bacteriophage. Such variations are not unexpected, for the ability to grow in the presence of substances which inhibit other organisms in any natural environment has obvious survival value. The plasticity afforded by variations in 
reaction by different strains to actinomycete inhibition would be important to heterogeneous soil populations of Fusarium spp. The main immediate value of these differences is that they provide a simple in ritro method of distinguishing between isolates of $\boldsymbol{F}$. oxysporum that otherwise are distinguishable only by laborious infection tests. Previously, during our experiments concerned with the genetics of pathogenicity in $F$. oxysporum, the only way of distinguishing in vitro between isolates used in combined infections was to produce biochemical or morphological mutants by such treatments as irradiation with ultraviolet light. We have found that mutants produced by these treatments are, however, usually decreased in their infectivity. A natural difference in ability to tolerate growth products of an actinomycete provides a test that avoids the complications introduced by artificial mutagenic methods, for the genetical 'markers' concerned with tolerance to inhibition are related to wild-type pathogenicity.

We wish to thank Dr F. A. Skinner of the Soil Microbiology Department, Rothamsted, for providing the actinomycete cultures.

\section{REFERENCES}

Buxton, E. W. (1955). Fusarium diseases of peas. Trans. Brit. mycol. Soc. 38, in press.

Katznelson, H. Sutton, M. D. (1953). Bacteriophage in relation to Xanthomonas translucens. Canad. J. Bot. 31, 725.

Kublanovskaya, G. M. (1952). Concerning the use of actinomycete-antagonists against Fusarium wilt of cotton. Microbiology, Moscowe, 21, 340.

Lachange, R-O. \& Perrault, C. (1953). Antagonisme des micro-organismes du sol envers Fusarium oxysporum f. lini, agent de la flétrissure du Lin. Canad. J. Bot. 31, 515.

Mitchison, D. A. (1951). The segregation of streptomycin-resistant variants of Mycobacterium tuberculosis into groups with characteristic levels of resistance. J. gen. Microbiol. 5, 596.

Snyder, W. C. \& Hansen, H. N. (1940). The species concept in Fusarium. Amer. J. Bot. 27, 64.

Wollenweber, H. W. \& Reinking, O. A. (1935). Die Fusarien. Berlin: Paul Parey.

\section{EXPLANATION OF PLATE}

Fig. 1. Differences in tolerance shown by Fusarium oxysporum f. pisi, race 2 (left) and F. oxysporum f. pisi, race 3 A (right) towards Streptomyces albidofiavus. $\left(\times \frac{2}{3}\right.$.)

Fig. 2. Zones of inhibition of $\boldsymbol{F}$. oxysporum f. pisi, race 2 (left) and F. oxysporum f. pisi, race 3 (right) caused by $S$. albidoflavus. $\left(\times \frac{2}{3}\right.$.)

Fig. 3. Effect of a culture filtrate of $S$. albidoflavus on three strains of $F$. oxysporum. $a, F$. oxysporum f. pisi, race 2 : strongly inhibited. ( $\times \frac{2}{3}$.) $b, F$. oxysporum f. gladioli, strain $F 1$ : mildly inhibited. $\left(\times \frac{2}{3}\right.$.) 
Journal of General Microbiology, Vol. 13, No. 1
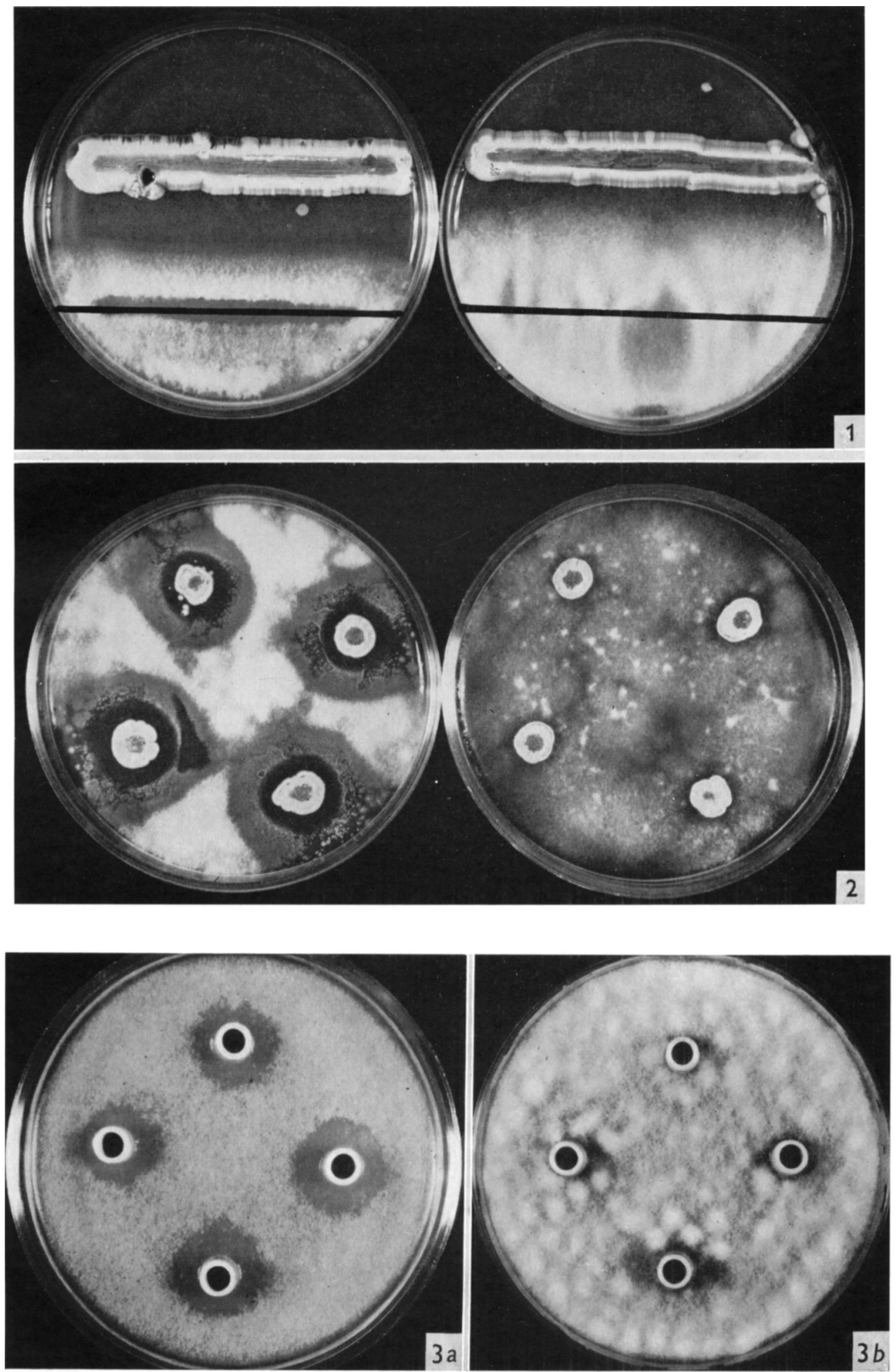

E. W. Buxton and M. G. Richards-Inhibitory distinction by actinomycetes. Plate 1 (Facing $p .102$ ) 